\title{
Nasal Intraosseous Hemangioma: A "Honeycomb" Lesion
}

Vaz de Castro $\mathrm{J}^{*}$, Andre $\mathbf{C}$ and Antunes $\mathbf{L}$

Department of Otorhinolaryngology, Head and Neck Surgery, Hospital Garcia de Orta, Portugal
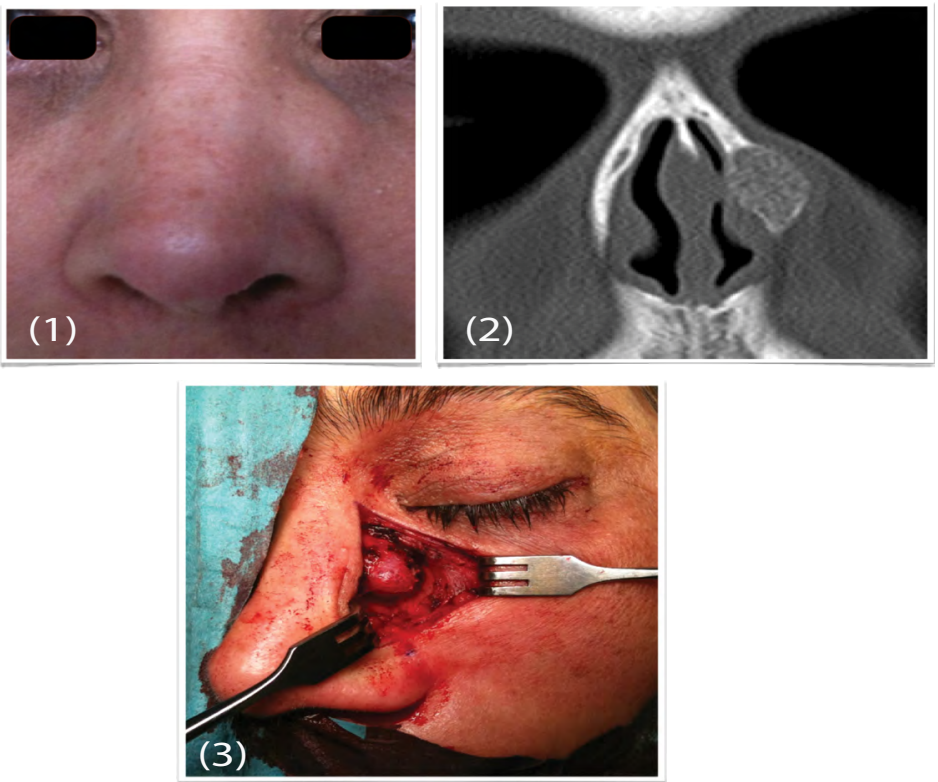

Figure 1: Mass located in the lateral aspect of the nose.

Figure 2: Suggestive imaging of intraosseous hemangioma on computer tomography. Figure 3: Surgical excision of the lesion through a Para lateral nasal approach.

\section{Clinical Image}

\section{Introduction}

Hemangiomas are benign lesions of the blood vessels or vascular elements, in the nose, they are a rarity, when intraosseous, even more so. When intraosseous hemangioma, characteristic imaging may suggest this diagnosis.

Keywords: Nasal hemangioma; Cavernous; Intraosseous imaging

\section{Case Presentation}

We describe the case of a 48-year-old woman manifesting a solid mass in the lateral aspect of the nose. Computer tomography (CT) of the Para nasal sinuses revealed an expansive lesion of the left lateral aspect of the nose, originating from the left nasal bone (Figure 1). This lesion appeared heterogeneous with calcifications in its interior, not disturbing adjacent tissues (Figure 2). Excised in an open nasal Para lateral approach (Figure 3), pathology analysis revealed an intraosseous hemangioma.

\section{Discussion}

Imaging characteristics that may contribute to the diagnosis of intraosseous hemangiomas include: a rounded unilocular with radial trabeculation lesion, with a honeycomb or soap balls pattern. Recommended treatment is surgical excision, for cure and posterior definitive histopathological diagnosis.

*Corresponding author: Dr. Joana Vaz de Castro, Hospital Garcia de Orta, Avenida Torrado da Silva, 280-915, Pragal, Almada, Portugal, Tel: +351 $212727295 ;$ E-mail: joanavazdecastro@gmail.com

Citation: Vaz de Castro J, Andre C, Antunes L (2017) Nasal Intraosseous Hemangioma: A “Honeycomb” Lesion. Int J Clin Med Imaging 4: 573. doi:10.4172/23760249.1000573

Copyright: (ㅇ 2017 Vaz de Castro J. et al. This is an open-access article distributed under the terms of the Creative Commons Attribution License, which permits unrestricted use, distribution, and reproduction in any medium, provided the original author and source are credited. 


\section{References}

1. Gomez OG, Guillermo G, Garcia-Rozado A, Alvaro, Luaces RR (2008) Intraosseous mandibular hemangioma. A case report and review of literature. Med Oral Patol Oral Cir Bucal 13: 496-498.

2. Kazuya T, Yukinori T, Michiko H (2010) Intraosseous hemangioma of the inferior turbinate. Case Rep Med: 409-429.

3. Vega A, Obieta E, Aguado G, Esqueda S, Ruiz E, et al. (2010) Hemangioma cavernoso multifocal en craneo. Revision de un caso. Neurocirurgia 21: 484-490.

4. Archontaki M, Stamou AK, Hajioannou JK, Korkolis DP, Kyrmizakis DE, et al. (2008) Cavernous haemangioma of the left nasal cavity. Acta Otorhinolaryngologica italic 28: 309-311.

5. Heckl S, Aschoff A, Kunze S (2002) Cavernomas of the skull: review of the literature 1975-2000. Neurosurg Rev 25: 56-62. 